non : when a helium-filled flask was placed in the beam emitted by the generator, a very bright discharge appeared in the helium and the walls of the quartz flask melted. This suggested to Kapitza that it might be possible to heat plasma to very high temperatures through the use of microwave techniques. He coupled a chamber in the form of a microwave resonator to a nigotron, and admitted various gases (helium, hydrogen, deuterium) under a pressure of 1-2 atm. Kapitza observed a filamentary discharge at the centre of the chamber (where the microwave intensity was highest). Applying various plasma diagnostic methods, he showed that the temperature of the plasma electrons in the discharge was about 1 MK. These studies, which Kapitza is still pursuing vigorously, opened a new road to the solution of the thermonuclear problem and enabled him to suggest the design of a reactor based on this principle.

Kapitza is more than a prominent scientist ; he is also a major scientific organizer. As director of the Institute for Physical Problems, a member of the Praesidium of the USSR Academy of Sciences, and the editor-in-chief of the country's leading physics journal, he devotes much effort to concrete scientific-organizational work. As in his science, he is also an innovator here, in search of the most progressive methods of administrating a mechanism as subtle as that represented by a creative scientific work-force.

Kapitza has always given much attention to the training and selection of young people who are capable of creative scientific work. He was one of the co-founders of the Moscow Physico-Technical Institute, and is the Chairman of the Coordination Council of this Institute. Kapitza himself invariably chairs the sessions of the State Examination Commission for MFTI students who have done their undergraduate work in the Institute for Physical Problems. He also reviews every examination that applicants sit for admission to graduate work and himself prepares a set of problems for each exam.

In addition, Kapitza has been a prominent social figure. All aspects of the development of human society excite him. He is a member of the Soviet National Committee of the Pugwash movement of scientists for peace and disarmament and participated actively in this movement. $\mathrm{He}$ has often taken a stand on questions of the future development of human society, especially in connection with such pressing problems as disarmament, pollution of the environment, and the ecological crisis.

\title{
Council Report from Rome
}

At the Rome Council meeting, where with one exception, chairmen from all the Divisions were present, the current vitality of EPS was much in evidence. Torrential rains gave little encouragement to members to stray away to study the attractions of the ancient city and a great deal of business was accomplished. Many of the delegates were fresh from the Seminar on the European Great Projects which was generally acknowledged to have been a singular success, establishing a precedent that will undoubtedly be followed up in the future. All too often in the past, different areas of physics have found themselves in competition, whereas the Seminar took place in an atmosphere of reciprocal understanding pointing the way to an intensification of collaboration in the future.

Participants in the Executive Committee meeting that preceded Council were invited to meet the President of the Italian Republic and join the EPS President in presenting the work of the Society to the political authorities of the host country. Later, members of Council had an audience of the Pope, when again the work of the Society was explained to a non-scientific authority - following the precepts of the President that physicists must make contact with the leaders of non-scientific milieux to transmit awareness of what the scientific community is trying to do.

\section{Advisory Committee Reports}

From amongst the topics presented to Council by the Advisory Committees, particular note was taken of the following :

ACAPPI: A study has been made in Sweden of the problem of closing the gap between pure and applied physics to the mutual advantage of both. Fundamental issues of general applicability were raised and Europhysics News hopes to publish a review of these in the near future.

Conference Committee: Applications for EPS approval or sponsorship are up on last year which suggests that we have not yet reached saturation. The young physicists solidarity fee levied on participants at approved conferences is still a subject of debate but until we find an alternative source of funds we have no other way of helping young people to attend the General Conferences. Not that everyone believes that this is necessarily the optimum way of using the fund but for the present no change is contemplated.

Following exchanges between the Presidents, tentative moves have been made to implement the generally expressed wish on both sides of the Atlantic for a closer contact between EPS and APS. One area of activity is the running of joint conferences and the Divisions are now studying what can most usefully be done.
Europhysics News: The President called for a closer identification of members with their journal including using it more for situations vacant advertising. As an experiment, effort will be devoted to attracting product advertising for special issues.

Physics and Education: Analysis of the study on secondary school education was nearing completion and when properly digested will be summarized in EN. The experiment at York with the workshops and lecture on Piaget philosophies was considered to have been of considerable value. The Committee was not wishing to act as a promotional front for Piaget methods but felt that a useful task had been done in exposing the principles and practice of Piaget's teaching to a wider audience.

The Committee had completed its study of the EPS Lecturer Exchange Scheme and Council was able to give the proposals its warmest approval. Details are presented on page 9. The organizers were urged to introduce the scheme with all possible speed in order to make sure that several lecturers were already in post by $\mathrm{Au}$ tumn 1980. Council members in their turn were asked to give wide publicity to the Scheme - a stricture that applies equally to the readers of $E u$ rophysics News.

Publications Committee: Revision of the Europhysics Style Manual has now been completed and will be published in the September issue of Europhysics News together with an abridged version of the ICSU AB classification. 


\section{European Journal of Physics: \\ Education}

Agreement had now been reached with the U.K. Institute of Physics on the terms for launching the new journal on education, with Professor G. W. Series as the first editor. (The Education Committee was concerned with the appointment of the 10 members of the Editorial Board nominated by EPS). The journal which will be "a journal of the EPS published by The I.o.P.", will be quarterly and will first appear in either the Spring or Summer of next year. It will deal with both education and scholarly studies in physics and will provide a forum for scholars and teachers of physics in Universities and other institutes of education.

The journal will publish articles in the following categories:

a) articles which are explicitly educational, that is, of a tutorial or pedagogical nature, on particular topics in physics, or relating to methods of teaching physics as practised in particular institutions or countries, or relating to the university training of school teachers: also occasionally on topics in physics at the interface between school and university;

b) articles of a reflective or speculative nature that bear on the fundamentals of physics or that offer new insights into known phenomena;

c) articles concerned with the interrelation between physics and other scientific disciplines;

d) occasional articles on the cultural implications of physics.

Articles will usually be published in English, but may be submitted in other European languages. Translations of titles and abstracts or extended synopses may be published in one or more languages. EPS and The I.o.P. share equally the profits or deficits, the commitment of EPS being limited to 20000 Sw.Fr. in any one year and 100000 Sw.Fr. total. Either party may withdraw at six month's notice.

Here is an explicit project that has attracted the attention of educational authorities and benevolent foundations in a number of countries. A. R. Mackintosh was able to announce that the Novo Foundation in Denmark had agreed to contribute to EPS, 30000 DK.Kr. to help towards the launching costs. This initial move, it is hoped, will stimulate others to seek similar donations or guarantees in their own country. It has often been said in Council that it is much easier to obtain funding for specific projects - particularly those that are expected to become profitable - than for the Society in general. Well then...!

\section{5th General Conference}

Reports from the Divisions about their future conferences demonstrated the difficulty of finding empty spaces in the calendar, which emphasises the need to determine quickly the venue and date of the EPS 5th General Conference for which $E$. Matthias of the Free University in Berlin has already agreed to be chairman of the international programme committee. The Executive Committee was empowered to come to a decision as soon as it has all the necessary information. A major preoccupation is to see how we can then assure a good attendance of young physicists.

\section{Finance and Budgets}

The provisional accounts for 1978 were approved as well as the budget for 1979. Two causes for satisfaction in 1978: the results follow almost exactly the budget, with a small excess expenditure $(\sim 5000 \mathrm{Sw} . \mathrm{Fr}$. in 400000 Sw.Fr.) more than compensated by a greater income ( 7500 Sw.Fr.). Second pleasing aspect: with reference to convertible currency only, the trading balance should be 10000 Sw.Fr., which can all go into the Special Development Fund now that the Society's accumulated deficit has been reduced to zero. In 1979, however it would have been very difficult

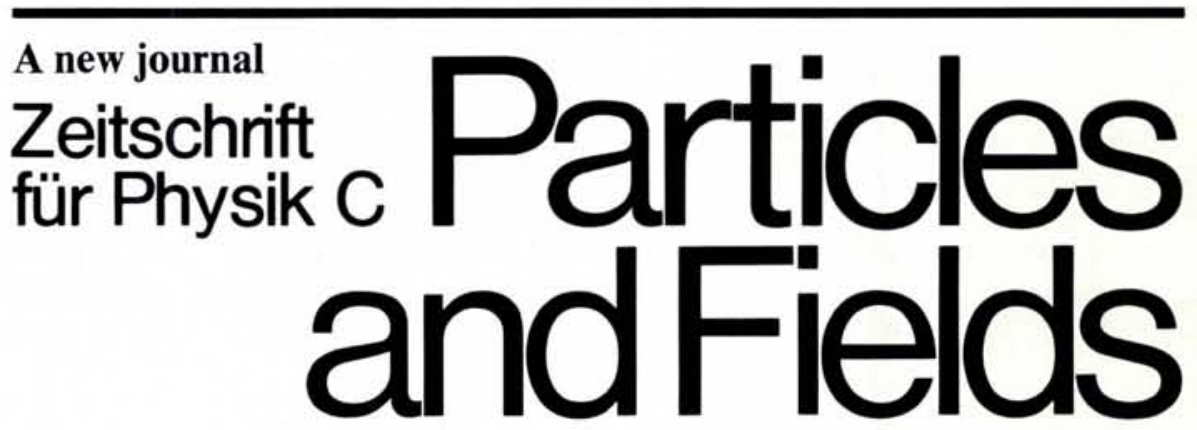

Subscription Information: 1979. Volumes $1-2$ ( 4 issues each). Sample copy upon request.

\section{North America:}

1979. US \$205.00, including postage and handling.

Subscriptions are entered with prepayment only. Send your order or request to your bookseller or to: Springer-Verlag New York Inc. 175 Fifth Avenue, New York, NY 10010, USA

\section{All other countries}

(except North America)

1979. DM $392,-$, plus postage and handling.

Send your order or request to your bookseller or directly to:

Springer-Verlag, Wissenschaftliche Information Zeitschriften,

Postfach 105280 , 6900 Heidelberg, FRG

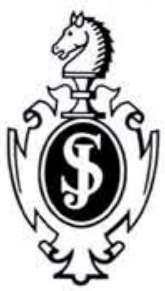

\section{Springer-Verlag}

Berlin

Heidelberg

New York
Editors in Chief:

G. Kramer, II. Institut für Theoretische Physik, Luruper Chaussee 149 , 2000 Hamburg 52, FRG

H. Satz, Fakultät für Physik, Universität Bielefeld, Postfach 8640 , 4800 Bielefeld 1, FRG

Editors: K. Fujikawa, Tokyo; K. Gottfried, Cornell; K. Kajantie, Helsinki; A. Krzywicki, Orsay; P. Landshoff, Cambridge; J. J. Sakurai, UCLA; P. Söding, DESY; B. Stech, Heidelberg; J. Steinberger, CERN

Aims and Scope: Zeitschrift für Physik C, Particles and Fields is devoted to the experimental and theoretical investigation of elementary particles. In view of the steadily growing interplay of theory and experiment in this field, particular emphasis is given to a clear and complete presentation of research.

The topics covered include: strong, electromagnetic, and weak interactions of elementary particles, the constituent structure of elementary particles, interactions and classification of constituents, and symmetry and unification schemes of different interactions.

Zeitschrift für Physik appears in three parts: A: Atoms and Nuclei, B: Condensed Matter and Quanta, C: Particles and Fields.

Each part may be ordered separately.

Coordinating editor for Zeitschrift für Physik, parts A, B and C: O. Haxel, Heidelberg.

Information for Authors: Zeitschrift für Physik C, Particles and Fields is devoted to the experimental and theoretical study of elementary particle physics. Submitted manuscripts should present original research; they may not be simultaneously submitted to other journals nor be published elsewhere.

All manuscripts should be in English and be prepared in accordance with Springer-Verlag's "Instructions to Authors" (available on request).

Normally, the length of an article should not exceed twenty printed pages; under special circumstances, e.g., for the comprehensive presentation of a complete experiment and its results, longer papers will be accepted. Manuscripts may be submitted to any editor of the journal.

There is no publication charge; fifty reprints per article will be provided to the author(s) free of charge. 
to approach this performance as costs creep up and the value of a number of revenues decline were it not for the expected receipts from selling the Proceedings of the Rome Seminar which are being printed by INFN under an arrangement that is very advantageous to EPS.

This throws into relief the urgent need for the increase in unit fee from 1 January, 1980, from 7 Sw.Fr. to 8 Sw.Fr. that Council agreed. Considering that the last increase dates back to 1976 , since when, a large deficit has been wiped out and a number of new initiatives have been taken, the Society can feel reasonably happy with its house-keeping.

Opinions on the extent to which contributions for 4 a) members should be reduced were about equally divided. The governing principle when EPS was founded was that it should not be financially advantageous to join the Society and not be member of a national society. In many countries, changes in currency values had resulted in an excessive penalization of this group - but the difference was uneven and the principle that carried the day was to select a new rate which implied no change in the 4 a) contributions for the coming period.

\section{Membership}

This led naturally to a discussion on how the number of Individual Ordinary Members, 4a) and 4c), can be materially increased. As a result, more countries will adopt the practice of permitting 4c) members to pay in their national currency through their national society. It was also recognized that a sustained effort must be made to keep the physics public informed and to use meetings for further recruitment. Individual efforts in the past, as for example in the NP Division have been very successful. It should however be normal practice at approved conferences, for literature on EPS to be available and for parti- cipants to be encouraged to apply for membership of EPS before they disperse. We should also reconsider a limited-time student membership to lead young physicists into establishing good habits. The strength of the Society lies in its members.

\section{Executive Committee}

The composition of the new Executive Committee was published last month. One notable omission from the previous committee will have been remarked, namely that of Marcel Guenin who had been member for the maximum period of five years and Secretary for four years. Guenin came to the Executive Committee, having led the special working party set up to study the Society's administration when the fortunes of the Society were at their lowest ebb. His contribution to EPS over these past years has been of the greatest significance and Council placed on record its warm appreciation.

\section{EPS Scholarships}

At its meeting in Rome, Council approved a modification to the rules covering the selection of scholars in order to simplify and stream-line procedures. In the future, the coordinator, Jean Muller, will be able to process applications immediately, referring to the Selection Board only those cases where a second opinion is deemed necessary.

\section{INFN}

In the April Issue of Europhysics News, details of the scholarships for $1979 / 80$ in Italy were given. These are all under the auspices of the "Istituto Nazionale di Fisica Nucleare" whose structure and functions are set out below. INFN, as reorganized by the law of 15 December 1971, has the institutional task of promoting, coordinating and performing experimental and theoretical research in the field of fundamental nuclear physics. In close cooperation with the Ministry of Foreign Affairs, INFN also looks after Italian participation in international activities in the field of fundamental nuclear physics at both the multilateral and bilateral levels.

INFN is an institution with an autonomous budget (amounting in 1979 to 25000 million It. Lire) operating under the control of the Ministry of Public Education, the Ministry of In- dustry and Trade and the Ministry for the Coordination of Scientific and Technological Research. President of the Institute is Antonino Zichichi, President of EPS.

INFN comprises 18 Research Units: 14 Sections, the National Centre for the Analysis of Photograms (CNAF, Bologna), and 3 National Laboratories: at Frascati near Rome, at Legnaro near Padua and the Southern National Laboratory of Catania. INFN Sections are to be found in the Institutes of Physics at the Universities of Turin, Genoa, MiIan, Pavia, Padua, Trieste, Bologna, Florence, Pisa, Rome, Naples, Bari, Catania and the Istituto Superiore di Sanità.

The staff of the INFN Sections comprises not only INFN employees but also a large number of University staff (very often holding management responsibilities) associated with INFN. On 31 December, 1978, the strength was made up of 897 INFN staff members and 1109 University staff members associated with INFN.

The most important aspects of the Institute's activity are:

- promotion and development of inter-University and international research programmes;

- development and co-ordination of national research in the sector of fundamental nuclear physics;
- patronage and promotion of didactic activities in the field of physics (with particular importance given to the fundamental nuclear physics sector) within Italian Universities.

The Institute's scientific activities are coordinated and carried out within five research sectors (Groups):

- Group I (Electronic Experiments) and Group II (Track Chambers) for elementary particle physics;

- Group III for the physics of nuclei;

- Group IV for theoretical physics;

- Group V for technical and technological developments.

A National Scientific Committee has been created for each of these Groups to advise the Council of the Institute on specific programmes of activities. A representative from each operative Research Unit of the Institute, elected by the researchers themselves, is present in each of the five National Scientific Commmittees.

In the field of international collaboration, INFN is assuring the promotion, the coordination and the financing of all the national activities carried out at CERN. It is also responsible for the activities of Italian research groups working within the framework of other international collaborations, such as those undertaken at a bilateral level with the scientific Institutions of France, Federal Republic of Germany, Great Britain, Soviet Union, U.S.A. etc.

INFN is also an Associate Member of EPS. 